\title{
The frequency of intestinal parasites in puppies from Mexican kennels
}

\author{
Enedina Jiménez-Cardoso ${ }^{1 *}$, Leticia Eligio-García ${ }^{1}$, Adrián Cortés-Campos ${ }^{1}$, \\ Apolinar Cano Estrada ${ }^{1}$, Margarita Pinto-Sagahón ${ }^{2}$, Cynthia Noguera-Estrada ${ }^{2}$ \\ ${ }^{1}$ Laboratorio de Investigación en Parasitología, Hospital Infantil de México FG, Dr. Márquez No. 162. Col. Doctores, D.F. 6720, \\ México; *Corresponding Author: enedina@servidor.unam.mx; \\ ${ }^{2}$ Fort Dodge Animal Health, Fort Dodge, USA.
}

Received 7 August 2010; revised 18 August 2010; accepted 30 August 2010.

\section{ABSTRACT}

The purpose of this investigation was to determine the intestinal parasite prevalence in puppies from six different kennels; four kennels were in Guadalajara and Zapopan cities (Jalisco State) and two kennels were in Mexico City. From October 2006 to November 2007, we collected 441 fecal samples from 147 puppies, both male and female, ranging from 1 to 36 months of age. Three samples from every puppy were analyzed by using the Faust technique. The prevalence found were as follows: Giardia intestinalis (genotype A and B) 6.8\%; Cystoisospora 21.08\%; Uncinaria $7.48 \%$; Toxocara canis $12.29 \%$ and multiparasitism (Giardia, Toxocara and Uncinaria) $4.76 \%$. The highest prevalence for both Giardia and Cystoisospora were found in 2-3month-old puppies; the highest prevalence for Toxocara canis was found in 3-4-month-old puppies. In the kennels of Mexico City we found mainly Giardia intestinalis, Cystoisospora to be most prevalent in Zapopan and Toxocara canis in Guadalajara. The high prevalence of intestinal parasites found in this study demonstrates an increased risk for infection in humans, as these animals are usually a common pet in many homes. This zoonotic phenomenon represents an important health problem for any community.

Keywords: Parasites; Giardia; Cystoisospora; Dogs

\section{INTRODUCTION}

The prevalence of intestinal parasites in dogs from kennels depends on several variables, including the kennels' geographic area, number of animals sharing space, and, most importantly, the sanitary conditions in which the dogs live. Epidemiological studies of intestinal parasites give us an idea of the zoonotic risk for dogs living in kennels as well as dogs living with a family as a domesticated pet.

Several studies from kennels in Australia showed a parasitic prevalence of $23.9 \%$, with $9.3 \%$ of the cases testing positive for Giardia intestinalis [1]. In Spain, a study showed a prevalence of parasites in $25 \%$ of those tested, with $6.0 \%$ of the cases testing positive for Toxocara canis and $10.0 \%$ testing positive for Cystoisospora [2]. In Greece, studies found a $26 \%$ parasitic prevalence, with $12.8 \%$ of the cases testing positive for Toxocara canis, $4.3 \%$ testing positive for Giardia duodenalis and Cystoisospora, and 2.8\% testing positive for Uncinaria [3]. These statistics are important, as multiple parasites are being found in puppies as young as six months; therefore, kennel owners should treat all of their animals for parasites to prevent the continued spread of gastrointestinal diseases [4]. For example, there is a high incidence of Giardia in children; this could be explained if the children are living in homes with a contaminated pet [5]. Deworming and treating all kennel animals for parasites would reduce the cases of infection in humans.

When puppies lived in a small, confined area in groups of 12 to 15 , especially in cases when they lived together with their mother, tests showed a high prevalence for Toxocara canis and Cystoisospora (36.4\%). In contrast, when puppies were kept in clean, spacious areas, these parasites were found in only $10 \%$ of those tested. Finally, some reports show that the prevalence of intestinal parasitism in dogs ranges from $35.5 \%$ to $100 \%$ [6]. For dogs kept in private kennels, the prevalence range is between $54 \%$ and $68 \%$ [7].

Intestinal parasitism can be an asymptomatic disease; moreover, there is no a specific symptom that can identify a parasite. Therefore, all puppies kept in a kennel or stored in similar places could receive a prophylactic treatment to prevent intestinal parasitic from spreading 
to children who have puppies at home [8]. We therefore conducted this investigation to elucidate the intestinal parasite prevalence in different kennels located in Mexico City and Jalisco State, with the hope of reducing the possible risk factors associated with human-puppy parasitic diseases.

\section{MATERIAL AND METHODS}

Identification and Prevalence of Parasites: From October 2006 to November 2007, we collected feces from 147 puppies (males and females) ranging from 1 to 36 months in age and obtained from six kennels, four of which were in Guadalajara and Zapopan cities (Jalisco State) and two of them were in Mexico City. The dogs were fed at libitum and they received no special care in their environment. We collected three samples from each animal on different days. Identification of the parasites was performed via the Faust technique [9], and the results were analyzed in relation to the dogs' ages, sexes, breed sizes and kennels. We considered data statistically significant when $\mathrm{p}<0.05$ with $95 \%$ confidence interval (CI), using SPSS 10-0 (Copyright 1999, SPSS Inc. program).

Genotype of Giardia: DNA was isolated from each puppy's fecal sample by using the fast DNA kit and the fast prep instrument (QBiogene, inc., CA). Then B-giardin gene from Giardia intestinalis was amplified using the nested-PCR method [10]. After PCR, electrophoresis in $1.5 \%$ agarose gel was performed. Next, in a $10 \mu \mathrm{L}$ reaction volume, restriction digest reaction contained $7 \mu \mathrm{L}$ of amplicon obtained from the nested-PCR reaction, 10 $\mathrm{mg} / \mathrm{mL}$ BSA and $10 \mathrm{U}$ of HaeIII enzyme [11]. We incubated this reaction mix at $37^{\circ} \mathrm{C}$ for 3 hours, and then analyzed the product using $2 \%$ agarose gel electrophoresis to determine the fragments obtained.

\section{RESULTS}

Identification and prevalence of parasites: The prevalence of Giardia intestinalis in dogs at different ages was $4.69 \%-6.8 \%$, (95\% CI, 2.11 to 11.49$)$, as is seen in Table 1. The highest prevalence occurred in dogs that were 2-3 months old. A statistical difference was observed between groups: those groups with dogs older than 3 months and those groups with dogs older than 11 months ( $p$ $<0.05$ ). In the same table, we have demonstrated that in Mexico City, kennel-housed animals had the highest rates of Giardia intestinalis $(\mathrm{p}=0.003)$. Other analyses did not show any statistical differences between breeds or breed size, while the location of kennel housing was important. The prevalence of both Cystoisospora and Toxocara in the puppies of Mexico City kennels was
Table 1. Prevalence of Giardia intestinalis in dogs from different ages and kennels.

\begin{tabular}{|c|c|c|c|c|}
\hline \multicolumn{5}{|c|}{ Giardia intestinalis } \\
\hline Age months & Total & $\mathbf{N}(+)$ & $95 \% \mathrm{CI}$ & p-value \\
\hline \multicolumn{5}{|l|}{ Dogs } \\
\hline$<1-2$ & 56 & 1 & $1.78-16.75$ & \\
\hline$>2-3$ & 48 & 6 & $12.50-9.35$ & 0.029 \\
\hline$>3-4$ & 23 & 1 & $4.34-8.33$ & N.S. \\
\hline$>4-5$ & 8 & 0 & 0 & - \\
\hline$>5-11$ & 5 & 1 & $20-35.06$ & 0.04 \\
\hline$>11$ & 7 & 1 & $14.28-25.92$ & N.S. \\
\hline Total & 147 & 10 & $2.11-11.49$ & \\
\hline \multicolumn{5}{|l|}{ Kennel } \\
\hline $\begin{array}{c}\text { Guadalajara, } \\
\text { Jal }\end{array}$ & 47 & 2 & $4.24 \pm 5.77$ & \\
\hline Zapopan, Jal & 28 & 0 & - & - \\
\hline Mexico City & 72 & 8 & $11.11-7.25$ & 0.003 \\
\hline Total & 147 & 10 & $6.80-4.07$ & \\
\hline \multicolumn{5}{|l|}{ Breed size } \\
\hline Small & 76 & 3 & $3.94-4.37$ & N.S. \\
\hline Medium & 43 & 5 & $11.62-9.58$ & N.S. \\
\hline Large & 28 & 2 & $7.14-9.53$ & N.S. \\
\hline Total & 147 & 10 & $6.80-4.07$ & \\
\hline
\end{tabular}

$\mathrm{N}(+)$ : Number of positives cases; $95 \%$ Confidence interval; $\mathrm{P}>0.05$; N.S Non significant

statistically unique. As seen in Table 2, we analyzed dogs 2-3-month old dogs and 3-4 month-old dogs. Multiple parasites were isolated in dogs older than 2-3 months old $(\mathrm{p}<0.002)$. Finally, Table 3 shows what parasites were prevalent in each kennel. The highest infestation rate in Mexico City was for Cystoisospora, and Toxocara was highest in Zapopan ( $\mathrm{p}<0.001)$. In Guadalajara, most cases showed a high prevalence for multiparasite infections. Notably, other analyses did not show statistical differences in breed and sex.

The Genotype of Giardia: as shown in Figure 1 one Giardia isolated was Genotype A2 and nine isolates were Genotype A1.

\section{DISCUSSION}

The prevalence of Giardia intestinalis in puppies from Mexican kennels was $6.8 \%$, with the highest value in dogs younger than 6 months old. Similar results have been published by others [6,12-14] However, a good 
Table 2. Prevalence of Cystoisospora, Toxocara and Uncinaria isolated from puppies in different ages.

\begin{tabular}{|c|c|c|c|c|c|c|c|c|c|c|c|c|c|c|}
\hline & & Cystoisospora & & & Uncinaria & & & Toxocara & & $\begin{array}{l}\text { Multi] } \\
\text { Toxoca }\end{array}$ & $\begin{array}{l}\text { parasites: }(G \\
\text { ara and } U n c i\end{array}$ & $\begin{array}{l}\text { iardia, } \\
\text { naria). }\end{array}$ & & \\
\hline $\begin{array}{c}\text { Age } \\
\text { (months) }\end{array}$ & $(+) / \mathbf{T}$ & $95 \%$ CI & $\mathbf{p}$ & $(+) / \mathbf{T}$ & $95 \% \mathrm{CI}$ & $\mathbf{p}$ & $(+) / \mathbf{T}$ & $95 \% \mathrm{CI}$ & $\mathbf{p}$ & $(+) / \mathbf{T}$ & $95 \%$ CI & $\mathbf{p}$ & $\mathrm{Neg} / \mathrm{T}$ & $\%$ \\
\hline$<1-2$ & $3 / 56$ & $5.35 \pm 5.89$ & NS & $0 / 56$ & 0 & - & $7 / 56$ & $12.5-8.66$ & NS & 0 & 0 & - & $46 / 56$ & 82.16 \\
\hline$>2-3$ & $14 / 48$ & $29.16 \pm 12.85$ & $\underline{0.003}$ & $8 / 48$ & $16.66 \pm 10.54$ & NS & $8 / 48$ & $16.66-10.54$ & NS & $5 / 48$ & $10.41-8.64$ & 0.002 & $13 / 48$ & 27.08 \\
\hline$>3-4$ & $11 / 23$ & $47.82 \pm 20.41$ & NS & $2 / 23$ & $8.69 \pm 11.51$ & NS & $2 / 23$ & $8.69-11.51$ & $\underline{0.01}$ & - & - & - & $8 / 23$ & 34.78 \\
\hline$>4-5$ & $2 / 8$ & $25 \pm 30$ & NS & $1 / 8$ & $12.5 \pm 22.91$ & NS & $2 / 8$ & $25-30$ & NS & $2 / 8$ & $25-30$ & NS & $1 / 8$ & 12.5 \\
\hline Total & $30 / 135$ & $21.08 \pm 6.59$ & & $11 / 135$ & $7.48 \pm 4.25$ & & $19 / 135$ & $14.07-5.42$ & & $7 / 56$ & $12.5-3.44$ & & $68 / 135$ & 50.37 \\
\hline
\end{tabular}

(+): positives cases; T: total; $95 \%$ Confidence interval; $P>0.05$; N.S. Non significant

Table 3. Prevalence of multiparasites found in each kennel.

\begin{tabular}{|c|c|c|c|c|c|c|c|c|c|c|c|c|c|c|}
\hline \multirow[b]{2}{*}{ Kennel } & \multicolumn{3}{|c|}{ Cystoisospora } & \multicolumn{3}{|c|}{ Uncinaria } & \multicolumn{3}{|c|}{ Toxocara } & \multicolumn{3}{|c|}{$\begin{array}{l}\text { Multiparasites: (Giardia, } \\
\text { Toxocara and Uncinaria). }\end{array}$} & \multirow[b]{2}{*}{$\mathrm{Neg} / \mathrm{T}$} & \multirow[b]{2}{*}{$\%$} \\
\hline & $(+) / \mathbf{T}$ & $\mathrm{CI} \pm 95 \%$ & $\mathbf{p}^{1}$ & $(+) / \mathbf{T}$ & $\mathrm{CI} \pm 95 \%$ & $p^{1}$ & $(+) / \mathbf{T}$ & $\mathrm{CI} \pm 95 \%$ & $\mathbf{p}^{1}$ & $(+) / \mathbf{T}$ & $\mathrm{CI} \pm 95 \%$ & $p^{1}$ & & \\
\hline $\begin{array}{l}\text { Guadalajara } \\
\text { Jalisco }\end{array}$ & $10 / 17$ & $21.27 \pm 11.7$ & NS & 0 & - & - & 0 & - & - & $1 / 47$ & $2.12 \pm 4.1$ & $\underline{0.03}$ & $36 / 47$ & 76.59 \\
\hline $\begin{array}{l}\text { Zapopan } \\
\text { Jalisco }\end{array}$ & $15 / 28$ & $53.57 \pm 18.4$ & NS & $2 / 28$ & $7.14 \pm 9.53$ & NS & $1 / 28$ & $3.57 \pm 6.8$ & $\underline{0.001}$ & $2 / 28$ & $7.14 \pm 9.5$ & NS & $8 / 28$ & 28.57 \\
\hline Mexico City & $6 / 72$ & $8.33 \pm 6.38$ & $\underline{0.001}$ & $9 / 72$ & $12.5 \pm 7.63$ & NS & $18 / 72$ & $25 \pm 10$ & NS & $4 / 72$ & $5.55 \pm 5.2$ & NS & $35 / 72$ & 48.61 \\
\hline Total & $31 / 147$ & $21.08 \pm 6.5$ & & $11 / 147$ & $7.48 \pm 4.25$ & & $19 / 147$ & $12.92 \pm 5.4$ & & $7 / 147$ & $4.76 \pm 3.4$ & & $79 / 147$ & 53.74 \\
\hline
\end{tabular}

$(+)$ : positives cases; T: total; $95 \%$ Confidence interval; P $>0.05$; N.S. Non significant

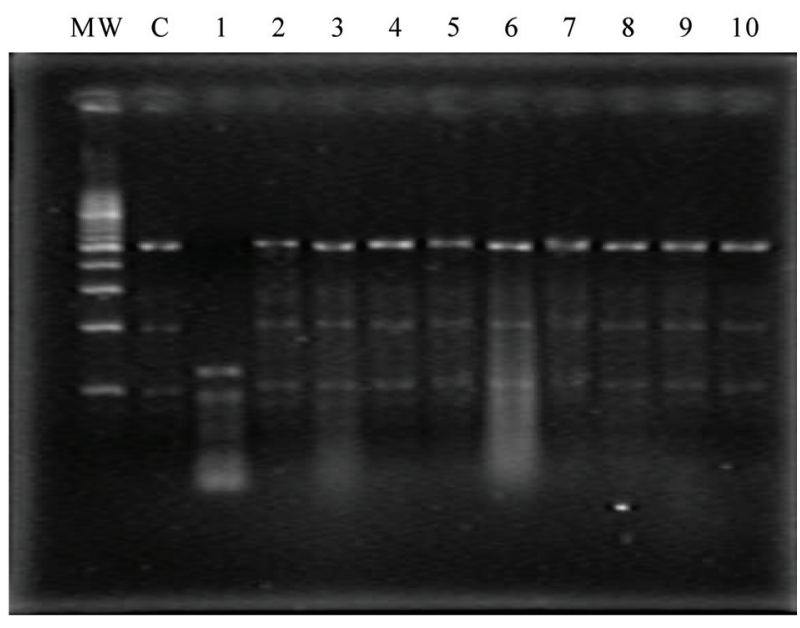

Figure 1. Genotype of Giardia intestinalis using B-giardina gene. MW - Molecular weights; CA Amplification control; Lane 1.- Genotype A2; Lanes 2-10 Genotype A1.

analysis should consider the following factors at least: geographic area; whether the kennel is private, public, or a business; number of animals living in the same space; hygiene standards; and feeding conditions. Determination of a Giardia genotype in the present investigation was important, as genotypes A and B are found in humans. Because the genotype found in nine samples was A1, whereas only one sample contained A2, and the fact that these samples were all collected from puppies living in different kennels, we can assume that we are facing a potential zoonotic problem in communities that house dogs taken from kennels [15].

The presence of several parasites (such as Giardia, Cystoisospora and Toxocara) that were observed in the present study have been studied and published by others $[4,5,16,17]$. This multiple parasitism could be the result of puppies becoming contaminated by their mother when they were very small or contracted from living in small, private spaces and/or lack of treatment due to the cost of preventive medication. In addition, Nikolić [18] reported that even inside private homes, there is a distinct prevalence of puppies with intestinal parasites. However, less than $50 \%$ of the animals we tested showed positive results for infection.

Toxocara canis infection is both an animal and a human health problem that has been described in the last decade, since it became possible to isolate Toxocara from dog's hair, public parks, gardens, and even indoor homes $[17,19,20]$. Furthermore, it is an important zoonotic problem [21-23]. In humans, the disease is referred as larva migrans, and it is considered an epidemiological disease [24].

This investigation demonstrates the importance of treating parasites in dogs, and recommends community programs be offered on pet handling and immunization 
to prevent further human infection, as some of the parasites have been isolated from both animals and humans, suggesting a problem stemming from veterinary-human interaction.

\section{REFERENCES}

[1] Palmer, C.S., Thompson, R.C., Traub, R.J., Rees, R. and Robertson, I.D. (2008) National study of the gastrointestinal parasites of dogs and cats in Australia. Veterinary Parasitology, 151(2-4), 181-190.

[2] Martínez-Carrasco, C., Berriatua, E., Garijo, M., Martínez, J., Alonso, F.D. and de Ybáñez, R.R. (2007) Epidemiological study of non-systemic parasitism in dogs in southeast Mediterranean Spain assessed by coprological and post-mortem examination. Zoonoses Public Health, 54(5), 195-203.

[3] Papazahariadou, M., Founta, A., Papadopoulos, E., Chliounakis, S., Antoniadou-Sotiriadou, K. and Theodorides, Y. (2007) Gastrointestinal parasites of shepherd and hunting dogs in the Serres Prefecture, Northern Greece. Veterinary Parasitology, 148(2), 170-173.

[4] Gal, A., Harrus, S., Arcoh, I., Lavy, E., Aizenberg, I., Mekuzas-Yisaschar, Y. and Baneth, G. (2007) Coinfection with multiple tick-borne and intestinal parasites in a 6week-old dog. The Canadian Veterinary Journal, 48(6), 619-622.

[5] Claerebout, E., Casaert, S., Dalemans, A.C., De Wilde, N., Levecke, B., Vercruysse, J. and Geurden, T. (2009) Giardia and other intestinal parasites in different dog populations in Northern Belgium. Veterinary Parasitology, 161(1-2), 41-46.

[6] Hamnes, I.S., Gjerde, B.K. and Robertson, L.J. (2007) A longitudinal study on the occurrence of Cryptosporidium and Giardia in dogs during their first year of life. Acta Veterinaria Scandinavica, 49, 22.

[7] Hird, D.W., Ruble, R.P., Reagor, S.G., Cronkhite, P.K. and Johnson, M.W. (1992) Morbidity and mortality in pups from pet stores and private sources: 968 cases (1987-1988). Journal of the American Veterinary Medical Association, 201, 471-474.

[8] Pullola, T., Vierimaa, J., Saari, S., Virtala, A.M., Nikander, S. and Sukura, A. (2006) Canine intestinal helminths in Finland: Prevalence, risk factors and endoparasite control practices. Veterinary Parasitology, 140(3), 321326.

[9] Faust, E.C., D’Antoni, J.S., Odom, V., Miller, M.J., Peres, C., Sawitz, W., Thomen, L.F., Tobie, L.E. and Walker, J.H. (1938) A critical study of clinical laboratory techniques for the diagnosis of protozoan cysts and helminth eggs in feces. American Journal of Tropical Medicine and Hygiene, 18(2), 169-183.

[10] Lalle, M., Jiménez-Cardosa, E., Caccio, S.M. and Pozio, E. (2005) Genotyping of Giardia duodenalis from humans and dogs from Mexico using a beta-giardin nested polymerase chain reaction assay. International Journal for Parasitology, 91(1), 203-205.

[11] Caccio, S.M., De Giacomo, M. and Pozio, E. (2002) Sequence analysis of the beta-giardin gene and development of a polymerase chain reaction-restriction fragment length polymorphism assay to genotype Giardia duodenalis cysts from human faecal samples. International Journal for Parasitology, 32(8), 1023-1030.

[12] Itoh, N., Muraoka, N., Saeki, H., Aoki, M. and Itagaki, T. (2005) Prevalence of Giardia intestinalis infection in dogs of breeding kennels in Japan. Journal of Veterinary Medical Science, 67(7), 717-718.

[13] Buehl, I.E., Prosl, H., Mundt, H.C., Tichy, A.G. and Joachim, A. (2006) Canine isosporosis - Epidemiology of field and experimental infections. Journal of Veterinary Medicine. B, Infectious Diseases and Veterinary Public Health, 53(10), 482-487.

[14] Meireles, P., Montiani-Ferreira, F. and Thomaz-Soccol, V. (2008) Survey of giardiosis in household and shelter dogs from metropolitan areas of Curitiba, Paraná state, Southern Brazil. Veterinary Parasitology, 152(3), 242-248.

[15] Solarczyk, P. and Majewska, A.C. (2010) A survey of the prevalence and genotypes of Giardia duodenalis infecting household and sheltered dogs. Parasitology Research, 106(5), 1015-1019.

[16] Mitchell, S.M., Zajac, A.M., Charles, S., Duncan, R.B. and Lindsay, D.S. (2007) Cystoisospora canis Nemeséri, 1959 (syn. Isospora canis), infections in dogs: Clinical signs, pathogenesis, and reproducible clinical disease in beagle dogs fed oocysts. International Journal for Parasitology, 93(2), 345-352.

[17] Roddie, G., Stafford, P., Holland, C. and Wolfe, A. (2008) Contamination of dog hair with eggs of Toxocara canis. Veterinary Parasitology, 152(1-2), 85-93.

[18] Nikolić, A., Dimitrijević, S., Katić-Radivojević, S., Klun, I., Bobrć, B. and Djurković-Djaković, O. (2008) High prevalence of intestinal zoonotic parasites in dogs from Belgrade, Serbia - short communication. Acta Veterinaria Hungarica, 56(3), 335-340.

[19] Holland, C., O'Connor, P., Taylor, M.R., Hughes, G., Girdwood, R.W. and Smith, H. (1991) Families, parks, gardens and toxocariasis. Scandinavian Journal of Infectious Diseases, 23(2), 225-231.

[20] Thompson, R.C. (2004). The zoonotic significance and molecular epidemiology of Giardia and giardiasis. Veterinary Parasitology, 126(1-2), 15-35.

[21] Itoh, N., Kanai, K., Hori, Y., Hoshi, F. and Higuchis, S. (2009) Prevalence of Giardia Intestinalis and other zoonotic intestinal parasites in private household dogs of the Hachinohe area in Aomori prefecture Japan in 1997, 2002, 2007. Journal of Veterinary Science, 68(2), 161163.

[22] Sowemimo, O.A. (2007) Prevalence and intensity of Toxocara canis (Werner, 1782) in dogs and its potential public health significance in Ile-Ife, Nigeria. Journal of Helminthology, 81(4), 433-438.

[23] Overgaauw, P.A., van Zutphen, L., Hoek, D., Yaya, F.O., Roelfsema, J., Pinelli, E., van Knapen, F. and Kortbeek, L.M. (2009) Zoonotic parasites in fecal samples and fur from dogs and cats in The Netherlands. Veterinary Parasitology, 163(1-2), 115-122.

[24] Lee, A.C., Schantz, P.M., Kazacos, K.R., Montgomery, S.P. and Bowman, D.D. (2010) Epidemiologic and zoonotic aspects of ascarid infections in dogs and cats. Trends in Parasitology, 26(4), 155-161. 